\title{
Haemosporidian infections affect antioxidant defences in great tits Parus major but are not related to exposure to aerial pollutants
}

\author{
DANIELA DE ANGELI DUTRA ${ }^{1}$, PATRÍCIA SILVEIRA ${ }^{1}$, JAIME ALBINO RAMOS ${ }^{2}$, \\ JOSÉ PAULO SOUSA ${ }^{3}$, ÉRIKA MARTINS BRAGA ${ }^{1}$ and ANA CLÁUdIA NORTE ${ }^{2}$ * \\ ${ }^{1}$ Departamento de Parasitologia, Instituto de Ciências Biológicas, Universidade Federal de Minas Gerais, Av. Antônio \\ Carlos 6627 Belo Horizonte, MG, 31270-901, Brazil \\ ${ }^{2}$ Department of Life Sciences, MARE - Marine and Environmental Sciences Centre, University of Coimbra, Largo \\ Marquês de Pombal, 3004-517, Coimbra, Portugal \\ ${ }^{3}$ Department of Life Sciences, Centre for Functional Ecology, University of Coimbra, Coimbra, Portugal
}

(Received 12 October 2016; revised 10 February 2017; accepted 17 February 2017)

\section{SUMMARY}

Haemosporidian parasites are widespread in avian species and modulate their ecology, behaviour, life-history and fitness. The prevalence of these vector-transmitted parasites varies with host intrinsic and extrinsic factors, such as host resistance and behaviour, and habitat-related characteristics. In this study, we evaluated the prevalence of avian haemosporidians in great tit Parus major populations inhabiting two areas with different degrees of exposure to aerial emissions from pulp mills, to assess if this type of pollution impacted parasite prevalence. We also compared the physiological condition of infected and uninfected individuals. Haemosporidian infection prevalence was high (58\%), varied seasonally, but was not associated with air pollution exposure. Fledged birds presented higher infection rates than nestlings and infected fledged birds had higher levels of blood glutathione peroxidase activity. These results allow us to infer that infection by blood parasites may activate antioxidant defences, possibly to protect the organism from the negative oxidative stress side-effects of immune activation against parasites. Because oxidative stress is one of the mechanisms responsible for ageing and senescence and may affect fitness, the relationship between parasitism and oxidative stress markers should be further investigated through studies that include experimental manipulation of infection in model organisms.

Key words: host-parasite interactions, haemosporidia, Plasmodium spp, glutathione peroxidase, oxidative stress, pulp mill, avian malaria.

\section{INTRODUCTION}

Environmental degradation and presence of pollutants are likely to negatively impact wildlife. Apart from their direct effect, pollutants may affect the organism susceptibility to infection through direct immunotoxic effects (by interfering with immune receptor binding and triggering inappropriate and/ or inhibiting immune responses), or through an increase of the overall stress levels of the organism which may lead to immunossupression (Dobson and Foufopoulos, 2001; Martin and Boruta, 2014). The knowledge of the effects of pollutants on avian immune function in the wild remains limited. Grasman et al. (1996) reported that fish-eating birds exposed to polyclorinated byphenyls showed inhibited T-cell mediated immunity, which might have been the cause for a high incidence of bacterial infections in these high trophic level birds. Also, great tits exposed to heavy metal pollution from a metallurgic smelter complex had a significantly

* Corresponding author: Department of Life Sciences, MARE - Marine and Environmental Sciences Centre, University of Coimbra, Largo Marquês de Pombal, 3004-517 Coimbra, Portugal. E-mail: acgnorte@ci.uc.pt lower humoral immune responsiveness than birds sampled in areas farther away from the from the pollution source, after immunostimulation by injection of sheep erythrocytes (Snoeijs et al. 2004). Environmental pollutants such as trace metals, have been reported to be associated with prevalence of Plasmodium infection in house sparrows Passer domesticus, suggesting immunotoxic effects of these contaminants (Bichet et al. 2013).

In this study, we aim to evaluate the haemosporidian community infecting great tit Parus major populations inhabiting two pine woods with different degrees of exposure to pollutants in west Portugal. We assessed the effect of environmental pollution (aerial emissions from pulp mills) on the prevalence of haemosporidians in those great tit populations. We also assessed the effects of haemosporidian infection on great tit physiology, namely on haematological, biochemical and morphological parameters, and whether their infection status was related with their ectoparasite levels. Haemosporidians are ubiquitous microscopic parasitic protozoa in birds, infecting blood cells and tissues and transmitted by blood-sucking insect vectors of the order Diptera (Valkiūnas, 2005).

Parasitology Open (2017), Vol. 3, e4; page 1 of 10. (C) Cambridge University Press 2017. This is an Open Access article, distributed under the terms of the Creative Commons Attribution licence (http://creativecommons.org/licenses/by/4.0/), which permits unrestricted re-use, distribution, and reproduction in any medium, provided the original work is properly cited. 
Those include the genera Plasmodium, Haemoproteus and Leucocytozoon, whose prevalence varies among geographical areas. Several factors affect the prevalence of these haemosporidians by affecting the presence/abundance of their vectors (climate and weather conditions, altitude, habitat conditions, including presence of freshwater bodies) and the susceptibility of the hosts (behaviour, phase of their life cycle, immune defences and resistance to a specific parasite), density of the host, among others (Sol et al. 2000; Valkiūnas, 2005; Ortego and Espada, 2007; Cellier-Holzem et al. 2010; Knowles et al. 2011; Isaksson et al. 2013).

Haemosporidians are costly to their hosts because they consume their host's metabolites and haemoglobin. Their effects can impair the organism in such a way that they may decrease its survival, leading directly (e.g. when invading naïve populations) or indirectly to its death, by decreasing its body condition and health, making it more vulnerable to predators and/or other diseases. They can also affect other life history traits such as decrease the breeding success of hosts (Merino et al. 2000; Marzal et al. 2005; Valkiūnas, 2005; Asghar et al. 2015). Reported effects of their infection on health status in the wild include decrease in body mass and condition (Figuerola et al. 1999; Garvin et al. 2006; Valkiūnas et al. 2006; Norte et al. 2009), decrease in total plasma proteins (Norte et al. 2009), decrease in haemoglobin levels (Norte et al. 2009; Krams et al. 2013), increase in total white blood cell (WBC) counts (Figuerola et al. 1999; Norte et al. 2009), modification of the leucocyte profiles (Ots and Hõrak, 1998; Fokidis et al. 2008; Norte et al. 2009), decrease in T-cell-mediated response to phytohemagglutinin (PHA response; Navarro et al. 2003) and increase in circulating immunoglobulin levels (Ots \& Hõrak, 1998). However, the magnitude of those effects depends on the degree of co-evolution between the parasite and host and is also linked to environmental conditions (Lindström et al. 2005).

Co-infections are common in nature [not only diptera-borne (Norte et al. 2009; Spurgin et al. 2012), tick-borne (Václav et al. 2011), but also among parasites with different transmission modes (Telfer et al. 2010)], which may be related not only with micro-habitat differences among individuals and degrees of exposure, but also with the individual's quality (ability to direct energy to immune defences and anti-parasitic activities), or because infection by one parasite increases susceptibility to other parasites. Because, at least during the feather growth period, feather mite loads have been found to negatively correlate with condition-dependent traits (feather quality and growth rates (Thompson et al. 1997; Pérez-Tris et al. 2002; Figuerola et al. 2003) we assessed if infection by haemosporidians had an effect on feather mite loads.
Moreover, some haemoparasites consume their hosts' haemoglobulin and lead to erythrocyte destruction causing anaemia (Campbell, 1994). Body condition and total plasma protein were evaluated as indicators of the host's nutritional status (Brown, 1996). Glutathione peroxidase is an antioxidant enzyme whose activity may increase to cope with reactive oxygen metabolites that may be produced during immune response to infection, to prevent oxidative damage to tissues (Ames et al. 1993). Total and differential WBC counts were assessed as indicators of the status of the immune system (Campbell, 1994), and also stress levels of the birds (Gross and Siegel, 1983). All these parameters (except haematocrit) were previously reported to correlate with haemoparasite infection in great tits (Norte et al. 2009). We expect that in the impacted area (that exposed to pulp mills aerial emissions) haemosporidian prevalence will be higher, except if exposure to pollution decreases vector abundance (Kozlov et al. 2005). We also expect that infected birds, especially nestlings and first-year birds during infection relapses (e.g. during demanding periods, such as the reproductive season for un-experienced first-year birds), will show signs of infection resulting for instance in anaemia, lower body condition and nutritional status, change in the WBC profile, increased antioxidant defences and higher feather mite loads, when compared with non-infected birds.

\section{MATERIALS AND METHODS}

\section{Study sites and sampling}

Great tits were captured in two pine woods of the Portuguese central west coast, near Figueira da Foz: Mata do Urso and Mata de Quiaios. Mata do Urso $\left(42^{\circ} 55 \mathrm{~N}, 7^{\circ} \mathrm{W}\right)$ is located in the vicinity of two pulp mill industrial complexes $(<1 \mathrm{~km}$ and 3 $\mathrm{km}$ to NE), and was defined as 'polluted'. Mata de Quiaios $\left(40^{\circ} 21^{\prime} \mathrm{N}, 8^{\circ} 85^{\prime} \mathrm{W}\right)$ is located ca. $20 \mathrm{~km}$ to the north of Mata do Urso. As prevalent winds in this area are from NNW, Mata de Quiaios is not exposed to pollution from the pulp mill complexes, and was defined as 'control'. These definitions of polluted and control, based on the distances to the pollution source (pulp mills), were latter supported by analysis of mercury levels in great tit feather samples living in those areas. The two study areas are very similar in terms of habitat conditions and their main difference resides on their exposure to anthropogenic influence (Norte et al. 2010).

The pulp mills of the study area produce bleached kraft pulp using an elemental chlorine-free method. Their gaseous effluents contain mostly carbon and sulphur oxides, organic and reduced sulphur compounds, nitrogen oxides and particles (StoraEnso, 2004, 2005), but may also contain volatile 
organochlorine compounds (Juuti et al. 1996), polycyclic aromatic hydrocarbons (PAH) and heavy metals from combustion of organic matter or fuel.

Birds were captured with mist nets from October 2004 to July 2005. During the breeding season both adults (when feeding 6-10 days old nestlings, hatching day $=$ day 0 ) and nestlings (with 14 days old) were sampled in the nest boxes. Each bird captured in the mist nets was sexed and aged (1 year or adult) according to their plumage. Basic morphological measurements [body mass $(\mathrm{g})$ and minimum tarsus length $(\mathrm{mm})$ ] were taken for all birds simultaneously to blood collection. Body condition index was obtained as the residuals of the linear regression of body mass on tarsus length (adults: $b=2 \cdot 25 \pm 3 \cdot 40$, $F_{1,73}=17 \cdot 80, \quad P<0.0001$; nestlings: $b=-0.38 \pm$ $\left.4 \cdot 58, F_{1,53}=12 \cdot 43, P<0 \cdot 0009\right)$.

Wing flight feather mite loads were quantified according to the method of Behnke et al. (1999) in fledged birds. We visually inspected both primary, secondary and tertiary flight feather of the wing of great tits using a score system from 1 to 3 for each feather $(0=0$ mites; $1=1-10$ mites; $2=11-30$ mites; $3=>30$ mites). The blood sample was collected from the brachial vein, and it was used to make a thin-film smear and the remaining blood was separated into plasma and erythrocytes fractions and frozen at $-80{ }^{\circ} \mathrm{C}$ for up to 45 days until analyses.

\section{Screening of blood parasites}

Blood smears were air dried and stained using the May-Grünwald-Giemsa method and scanned under $1000 \times$ magnification for $\mathrm{WBC}$ and heterophil/lymphocyte ratio $(\mathrm{H} / \mathrm{L})$ assessments. WBC count stands for the estimation of number of WBCs in approximately 10000 erythrocytes. The $\mathrm{H} / \mathrm{L}$ was measured by examining 50 WBCs because the repeatability of measurements on 50 and 100 WBCs was very high $(r=0.94 \pm 0.01$, $\left.F_{1,109}=31 \cdot 86, P<0 \cdot 001\right)$.

Blood smears were screened for 10-15 min at low magnification $(\times 400)$ to detect Leucocytozoon sp., Trypanosoma sp. and microfilaria. For the detection of Plasmodium and Haemoproteus, 200 fields were observed under oil immersion (at 1000× magnification) using Olympus Microscope CX31 (Olympus Corporation, Tokyo, Japan; (Valkiūnas, 2005).

\section{Physiological markers' assays}

Total plasma protein (protein - $\mathrm{mg} \mathrm{mL}^{-1}$ ) was measured using the Bradford Protein Assay, based on the Bradford dye-binding procedure (Bradford, 1976). For glutathione-peroxidase measurements (GPx; $\mu \mathrm{M} \min ^{-1} \mathrm{~g}^{-1}$ haemoglobin) we used the method of Paglia and Valentine (1967) as modified by Silva and Santos (1991), which consisted of measuring the rate of oxidized glutathione (GSSG) formation at $340 \mathrm{nM}$ as NADPH is converted to NADP+. Enzymatic activity and total protein were measured in a Sunrise Inst. Microplate reader. Hematocrit (Hct) was measured as the percentage of the length of the part of the capillary tube occupied by erythrocytes in relation to the total length of the capillary tube occupied by blood, after its centrifugation for $10 \mathrm{~min}$ at $1032 \mathrm{~g}$. Erythrocyte haemoglobin index ( $\mathrm{Hb} ; \mathrm{g} \mathrm{L}^{-1}$ ) was defined as the haemoglobin content in the $4 \times$ diluted haemolysate of erythrocytes and was not equivalent to whole blood haemoglobin concentration or dependent on hematocrit. It was measured with the cyanmethaemoglobin method at a wavelength of $540 \mathrm{~nm}$ (van Kampen and Zijlstra, 1961) using a commercial kit (BioSystems S.A., Barcelona, Spain). Haemoglobin was measured in addition to Hct because it may be a more sensitive and long-lasting indicator of anaemia (O’Brien et al. 2001; Norte et al. 2009).

\section{Statistical analysis}

Recaptured birds within 60 days of the first capture were excluded from the analyses; therefore, birds captured within the same season were not included, which gives time for the birds to recover of any effects of blood sampling on physiological parameters of interest. Only eight birds (8/138) were captured twice over different seasons and were included in the analyses. We evaluated if morphological and physiological parameters and feather mite loads were correlated with each other in fledged and nestling birds separately using Spearman correlations (Table S1). We compared prevalence of infection between nestling and fledged birds with a MannWhitney test using the mean prevalence of infection per nest. Because infection prevalence was significantly different among these groups (see below), further analyses were performed separately. Also, because nestlings are actively growing, their physiology is different (Kostelecka-Myrcha et al. 1973), and this should be taken into account when analysing and interpreting the data.

We evaluated how infection by haemosporidians in fledged birds was affected by intrinsic (age, sex) and extrinsic factors (season, pollution exposure) using Generalized Linear Models, with binomial distributions and logit link function. We used a stepwise approach, by including all explanatory variables in the models at first and removing them one by one, until the model contained only significant explanatory variables. Interactions between significant variables were also tested for significance and model improvement. Only the extrinsic effect of pollution exposure was tested on nestling infection status using a Mann-Whitney test using the mean prevalence per nest. The effects of infection by haemosporidians on the physiology of both fledged birds and nestlings was tested separately using General 
Linear Models with standard least squares estimations for normally distributed response variables with homogeneous variances (weight, body condition, HCT, GPx, WBC and H/L), or with Generalized Linear Models, with normal distribution and identity link function for normally distributed response variables whose variances were not homogeneous (protein and $\mathrm{Hb}$ ), or with Poisson distribution and $\log$ function for the response variables reflecting wing flight feather mite loads (total mite loads, primary feathers mite loads or secondary and tertiary feather mite loads). In these models, the infection status was included as explanatory variable along with any other potential covariables, such as pollution exposure (for fledged and nestling birds) season, sex and age (for fledged birds only). Nonsignificant variables were removed one by one until the model only included significant explanatory variables. Interactions between significant variables were also tested for significance and model improvement. WBC was square-root transformed and feather mite loads, H/L and protein were $\ln$ transformed for normality. When modelling the effects of infection on the physiological parameters of nestling birds, the factor 'nest' was included as a random effect to control for nestlings from the same nest. Only models in which infection status remained a significant explanatory variable are presented. In these models, we considered a bird to be infected if a Haemosporida was detected at the microscope, excluding those that were infected by Leucocytozoon only $(n=2)$. Statistical analyses were performed in JMP 6 (SAS Institute). Results are presented with mean \pm s.E.

\section{RESULTS}

\section{Microscopic analysis of blood smears}

Blood samples were collected from 138 birds. From these 118 smears were viable for microscope evaluation (50 from the control site and 68 from the polluted site) and haemosporidian screening: 75 from fledged birds and 43 from nestling birds (Table 1). Analysis of infection through microscopy resulted

Table 1. Sample size and total haemosporidian prevalence per great tits' age group and study area according to pollution exposure (Mata de Quiaios control area and Mata do Urso - polluted area)

\begin{tabular}{llll}
\hline \hline $\begin{array}{l}\text { Great tits, } \\
\text { age group }\end{array}$ & $\begin{array}{l}\text { Exposure to } \\
\text { pollution }\end{array}$ & $\begin{array}{l}\text { Sample } \\
\text { size }\end{array}$ & $\begin{array}{l}\text { Total } \\
\text { haemosporidian } \\
\text { prevalence (\%) }\end{array}$ \\
\hline $\begin{array}{l}\text { Fledged } \\
\text { birds }\end{array}$ & $\begin{array}{l}\text { Control area } \\
\text { Polluted area }\end{array}$ & 39 & $71 \cdot 8(28 / 39)$ \\
Nestling & $\begin{array}{l}\text { Control area } \\
\text { birds }\end{array}$ & 11 & $66 \cdot 7(24 / 36)$ \\
Polluted area & 32 & $34 \cdot 5(6 / 11)$ \\
\hline \hline
\end{tabular}

in an infection prevalence by haemosporidians of $58 \cdot 0 \%(69 / 118)$. Because of low parasitaemia intensity, it was not possible to morphologically distinguish between Plasmodium and Haemoproteus genera for 56 infected birds. In those smears, we observed young intra-erythrocytic forms that can be attributed to both Plasmodium and Haemoproteus genera. Among the identified genus, Plasmodium was the most prevalent haemoparasite $9 \cdot 3 \%(11 / 118)$, but Leucocytozoon was also detected $2 \cdot 5 \%$ (3/118). One bird showed co-infection with Plasmodium and Leucocytozoon. Infection prevalence differed significantly between fledged and nestling birds (nestlings: 17/43; fledged birds: $\left.52 / 75 ; Z_{1,86}=-2 \cdot 24, P=0 \cdot 025\right)$. No microfilaria or Trypanosoma were detected. The lack of detection of microfilaria in blood smears may be explained by the low circulation of these parasites in the blood stream, and the need of a higher volume of blood for its detection.

The identification of Plasmodium and Leucocytozoon was only possible at the genus level due to low parasitaemia (Figs 1 and 2). All morphologic erythrocytic stages of Plasmodium (trophozoites, erythrocytic meronts and gametocytes) were found during microscopic analysis (Fig $1 \mathrm{~A}-\mathrm{F})$. However, these forms were not observed in sufficient number to allow classification at the species level. Plasmodium spp. was found commonly in mature erythrocytes and presented as main characteristic the size of the erythrocyte meronts and gametocytes, which exceeded the size of nuclei from infected erythrocytes. Moreover, the mature erythrocytic meronts showed 10-16 merozoites (Fig. 1C and D). Leucocytozoon spp. (Fig. 2A $-\mathrm{F}$ ) presented as main characteristics erythrocytic forms restricted to macrogametocytes and microgametocytes and absence of malarial pigments (Fig. 2A-D and E and $\mathrm{F}$, respectively). Furthermore, the mature gametocytes of these parasites caused severe displacement of the nucleus from host cells making them morphologically rounded. In addition, the cytoplasm of these parasites contained small vacuoles (Fig. 2B).

\section{Correlates of infection in nestling birds}

No effects of being raised in the area exposed to aerial pollutants from pulp mills was detected on prevalence of haemosporidian infection $\left(Z_{1},{ }_{11}=\right.$ $0 \cdot 65, P=0 \cdot 51)$. No effects of infection by haemoparasites were detected on any of the physiological parameters evaluated (all $P>0 \cdot 05$ ).

\section{Correlates of infection in fledged birds}

Haemosporidian infection in fledged birds was affected by season (prevalence autumn $=25 / 37$; winter $=20 / 23 ; \quad$ spring $=7 / 15 ; \quad$ estimate $\quad[$ spring $]$ 

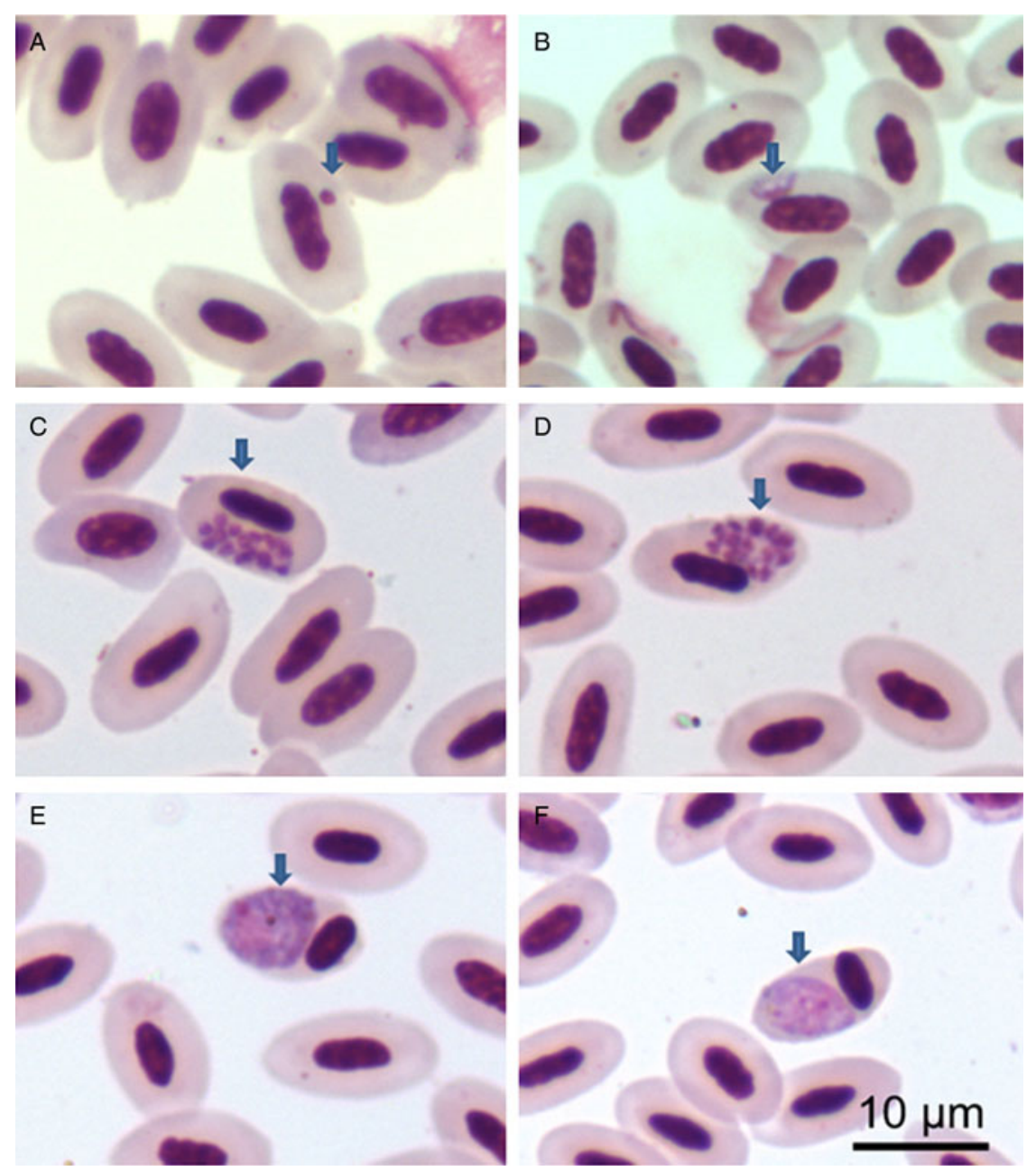

Fig. 1. Plasmodium spp. observed in May-Grünwald-Giemsa-stained blood smears from great tits (Parus major). (A, B) trophozoites; (C, D) erythrocytic meronts; (E) macrogametocyte and, (F) microgametocyte. Arrows indicate infected erythrocytes.

$=-1 \cdot 16 \pm 0 \cdot 37 ;$ estimate $[$ winter $]=1 \cdot 09 \pm 0 \cdot 41, \chi_{2,79}^{2}$ $=11 \cdot 69, P=0 \cdot 003$ ) with higher infection prevalence in winter and lower in spring.

Haemosporidian infection affected GPx activity of fledged birds with infected birds having higher GPx antioxidant activity levels (Table 2, Fig. 3). In the same model, GPx was also affected by the age of the bird, and exposure to aerial pollution (with higher values for older birds, and in the study area near pulp mills; Table 2). Total feather mite scores varied between 0 and 50, but did not differ significantly between Haemosporida infected and noninfected birds (mean \pm s.E. infected $=7 \cdot 5 \pm 1 \cdot 33$; non-infected: $6 \cdot 3 \pm 1 \cdot 66$ ). Primary feather and secondary and tertiary feather mite scores also did not differ significantly between infected and noninfected birds. None of the other measured morphological and physiological parameters were affected by infection status $(P>0 \cdot 05)$.

\section{DISCUSSION}

Our results do not support the hypothesis that haemosporidian infection is related with anthropogenic pressure, in the form of exposure to pulp mill aerial emissions. Anthropogenic habitat degradation may alter habitat condition for parasites, vectors and hosts, thereby altering prevalence and intensity of parasitism. Prevalence of haemoparasites in impacted areas may be lower than in conserved areas, but this depends on study areas/habitat types and parasite lineages (Chasar et al. 2009; Evans et al. 2009). In the specific case of the impact of pollutants, they can have direct immunotoxic effects on the host by inhibiting its immune system or contribute to the stress of the organism and increase its corticosterone levels, and its ability to cope with parasites (Martin and Boruta, 2014). Air emissions from pulp mills result mainly from the combustion of fuels to produce energy for pulp making processes. The gaseous effluents contain carbon dioxide and sulphur dioxide, and other sulphur oxides, reduced sulphur and organic sulphur compounds, nitrogen oxides ( $\mathrm{NO} x$ ), carbon monoxide and particles $[26,27]$. They may also contain volatile organochlorine compounds [28], PAH and metals from the combustion of organic matter or fuel. In a previous study (Norte et al. 2010) found that 

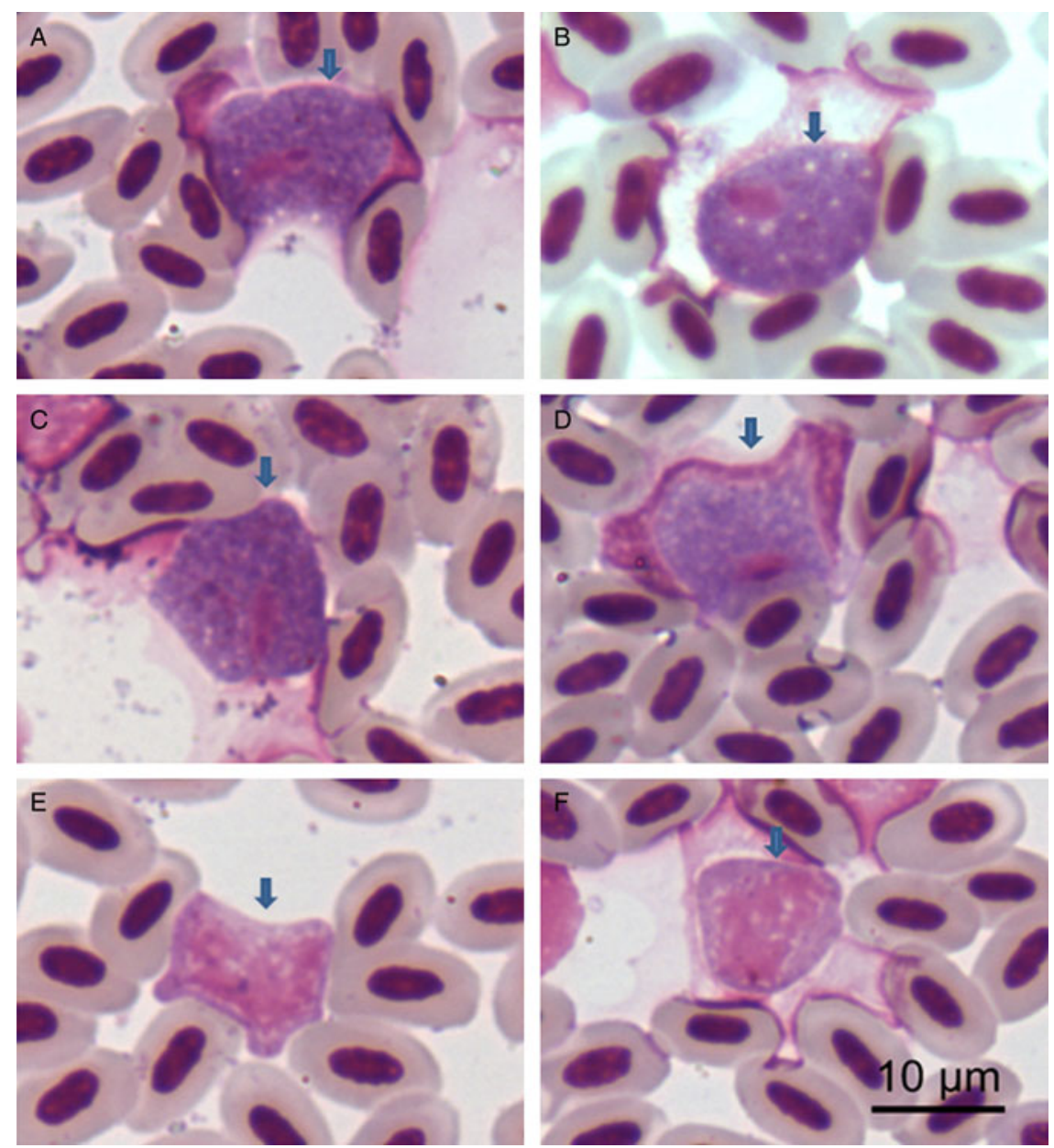

Fig. 2. Leucocytozoon spp. observed in May-Grünwald-Giemsa-stained blood smears from great tits (Parus major). (A-D) macrogametocytes and (E, F) microgametocytes. Arrows indicate infected erythrocytes.

mercury concentration in great tit feather samples from Mata do Urso, near the pulp mill complexes, was significantly higher than the nearby unpolluted control area, Mata de Quiaios. Trace metals were shown to depress the immune system in birds (Snoeijs et al. 2004) and mercury, in particular, was reported to depress the immune system (Kenow et al. 2007; Hawley et al. 2009), both in captivity and in the wild. However, in this study, we found no effects of pollution exposure on the prevalence of haemosporidians. Nonetheless, because we compared only two study areas, although chosen in order to be as similar as possible, we cannot exclude the hypothesis that they could have differed in other environmental characteristic, besides pollution exposure, that may have affected haemosporidian prevalence and confounded our results. We also found no evidence from the physiological profile of great tits (WBC or $\mathrm{H} / \mathrm{L}$ ) that that they differed between polluted or control areas in their immune status.

Prevalence of haemosporidians is often reported to vary seasonally, which is related with the fluctuations in populations of vectors, but also

Table 2. General Linear Model of the effects of haemosporidian infection and other co-variables (exposure to pollution and age) on glutathione-peroxidase activity of great tits Parus major

\begin{tabular}{|c|c|c|c|}
\hline \multirow[t]{2}{*}{$\begin{array}{l}\text { GPx } \\
\text { Model fit }\end{array}$} & \multicolumn{3}{|c|}{$R^{2}=0 \cdot 22 ; F=6.63 ; P<0.0005 ; n=73$} \\
\hline & Estimate \pm s.E. & $t$ & $P$ \\
\hline Intercept & $11 \cdot 86 \pm 0 \cdot 27$ & 43.99 & $<0 \cdot 0001$ \\
\hline Haemosporidian infection [infected] & $0.60 \pm 0 \cdot 27$ & $2 \cdot 24$ & 0.029 \\
\hline Pollution exposure [polluted] & $0 \cdot 58 \pm 0 \cdot 25$ & $2 \cdot 31$ & $0 \cdot 024$ \\
\hline Age [adult] & $0 \cdot 70 \pm 0 \cdot 25$ & $2 \cdot 75$ & $0 \cdot 008$ \\
\hline
\end{tabular}

Final models include only significant variables. 


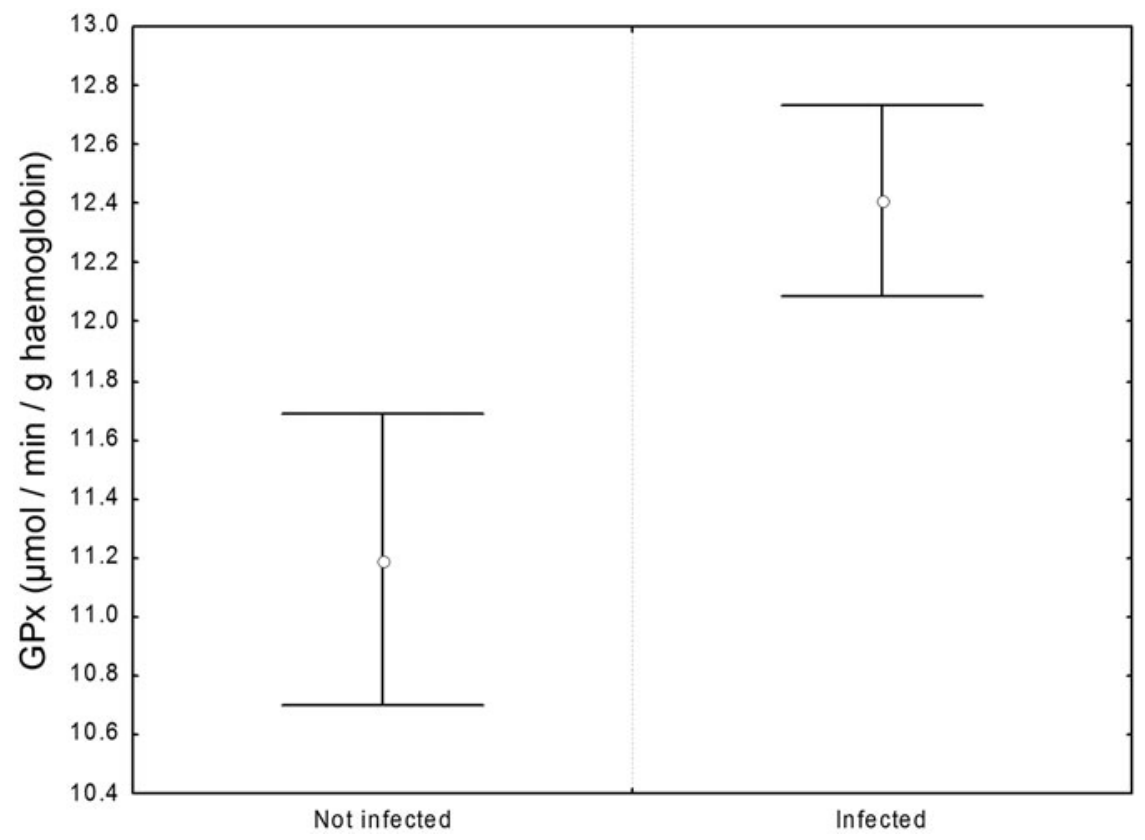

Fig. 3. Observed mean \pm s.E. of erythrocyte glutathione peroxidase activity of great tits (Parus major) infected and notinfected by haemosporidians (Plasmodium and Haemoproteus).

susceptibility of the hosts, associated with energy demanding periods of their life cycles. Haemosporidian prevalence usually increases in spring in temperate regions (Hatchwell et al. 2000; Norte et al. 2009), and an autumn peak may also be observed (Cosgrove et al. 2008). In this study, we found that haemosporidian prevalence had a different pattern, being lower in spring, intermediate in autumn and higher in winter. Ventim et al. (2012) also found that Plasmodium infections in Cetia cetti and $P$. domesticus increased from spring, to autumn and winter in Portuguese reedbeds, which could be related with lower food availability in those habitats during those periods compared with spring, making the birds more vulnerable to infections. This may also occur in pine woods, a relatively poor habitat, compared with deciduous and mixed woods, in which the majority of European studies were performed.

Interestingly we found that fledged birds infected with haemosporidians had higher levels of glutathione peroxidase. This effect was significant even after controlling for the effects of pollution exposure and age, which also increased GPx antioxidant activity. This may be explained by the activation of the immune system in response to parasite infection through cell-mediated immune response and inflammation mechanisms (Isaksson et al. 2013). This increases the levels of reactive oxygen species, which are released by heterophils to attack the parasite. Because this response in not specific and does not distinguish between self and parasite tissue, it may cause oxidative damage to all types of adjacent molecules and can lead to haemolysis and cellular dysfunction, increasing the risk of oxidative stress to the organism (Isaksson et al. 2013). The increase of glutathione peroxidase activity may be one protective action to recover from the potential unbalance in oxidative status (Meister and Anderson, 1983). Our previous study, in a nearby mixed deciduous woodland, also showed that both Plasmodium and Leucocytozoon infected great tits had significantly higher glutathione peroxidase activity (Norte et al. 2009). Isaksson et al. (2013) also reported that the levels of total and oxidized glutathione in great tits were significantly affected by the Plasmodium infection status, which could be related with the activity of glutathione peroxidase (Meister and Anderson, 1983). Moreover, a metaanalysis has shown that oxidative stress may indeed be a physiological cost of immune activation because the activation of the immune response changes oxidative stress markers, including glutathione peroxidase activity, although the direction of the effect may not always be consistent (Costantini and Møller, 2009). Therefore, it is important to measure a set of oxidative stress markers to have a better picture of the oxidative status of the organism because different protective mechanisms may be activated at different stages (Costantini and Møller, 2009). Although haemosporidian infection may have elicited an immune response and inflammation in infected birds, this was not reflected in the total and differential leukocyte counts, although Plasmodium, Haemoproteus and Leucocytozoon have been shown to cause leucocytosis (Figuerola et al. 1999). Glutatione peroxidase activity was also affected by pollution exposure, with higher values in birds inhabiting the vicinity of pulp mills. This confirms previous results that great tits exposed to 
aerial emissions from pulp mills show upregulated antioxidant defence mechanisms (Norte et al. 2010).

We did not find effects of haemosporidian infection in haemoglobin or haematocrit levels, which is in accordance with Dufva (1996). A literature review showed that results have been contraditory concerning the relationships between haematocrit and haematozoan parasite infection (Fair et al. 2007), but haemoglobin levels have been reported to be more sensitive indicators of parasite induced anaemia (Norte et al. 2009). Also birds suffering from anaemia may move less and be less often captured making it difficult to detect such relationships in wildlife studies. Possibly, the birds in our study were in the chronic phase of infection, as suggested by the low parasitaemia intensity observed in their blood smears, and anaemia is noticeable mainly during the acute phase of infection (Cornet et al. 2013).

We did not find an association among haemosporidians and feather mite infestation loads. Positive associations between blood parasites and other parasite types, with different transmission modes, especially ectoparasites, have not been commonly found in nature. Kleindorfer et al. (2006) and Norte et al. (2013) found no association between blood parasite infection and tick infestation loads, possibly due to different branches of the immune system acting against different parasites; also, these associations may only be detectable at high infection rates. But Telfer et al. (2010) revealed that infections by cowpox virus (directly transmitted), Babesia microti (tick-transmitted), Bartonella spp. (flea-transmitted) and Anaplasma phagocytophilum (tick-transmitted) were connected in field voles (Microtus agrestis), supporting the increased susceptibility hypothesis. Although, in our study, primary feather mite loads were negatively correlated with body condition, suggesting that they could be indicators of the individuals' quality, we did not find an association among them and haemosporidian infection. The relatively small sample size of our study might have limited the detection of other potential relationships between infection and physiological markers or the detection of other environmental factors that might affect infection status. Also, because different haemosporidian genera have different ecologies and habitat/vector requirements, the hemosporidian genera identification through molecular methods should help to detect environmental relationships.

The prevalence of haemosporidian infection reported in this study $(58 \%)$ was higher than that reported for fledged great tits inhabiting a mixed wood in Portugal situated approximately $40 \mathrm{~km}$ away (31.2\%; Norte et al. 2009). In that population, Plasmodium was also the most common Haemosporida, just as in the study by Antunes (2007) in passerines in central Portugal, in which the most prevalent haemoparasite was Plasmodium, followed by
Leucocytozoon and by Haemoproteus. Variation in the prevalence of haemosporidian parasites is expected, even at small spatial scales, and related with habitat and host characteristics, vector abundance and interactions among these variables (Shurulinkov and Chakarov, 2006; Knowles et al. 2011; Isaksson et al. 2013). We detected no Trypanosoma infection in this study, which agrees with the lower prevalence of Trypanosoma in great tits previously reported for Central Portugal (1\%; Norte et al. 2009). Moreover, to our knowledge there are also no reports of microfilaria in Portugal from avian blood smears (Tomás, 2014). The fact that this study was based on the microscopic evaluation of blood smears might have underestimated the prevalence of blood parasites, especially in lowintensity infections and/or during their chronic phase, when there are no gametocytes in circulation. However, similar prevalences of malarial and Leucocytozoon parasites may be obtained by microscopy and PCR-based techniques in naturally infected birds if good-quality smears are examined by skilled investigators (Valkiūnas et al. 2008). The fact that fledged birds presented a higher prevalence of infection than nestling birds was expected given the higher probability of previous contact with infected vectors (Wood et al. 2007). This was shown for house martins (Delichon urbica) as the probability of blood parasite infection increased as individuals age (Marzal et al. 2015), which, may also be explained by immunosenescence (Knowles et al. 2011). However, a decrease in prevalence of blood parasites with age has also been reported, depending on the genus/lineage of the parasite. Sol et al. (2003) showed that Haemoproteus infections declined as hosts age, which may be explained by acquired immunity (Knowles et al. 2011). Although the prepatent period varies with haemosporidian genera and species (from 2 days to several months (Valkiūnas, 2005), we detected infected nestlings when they were only 15 days old, meaning that they were infected in their first days of life. Prevalent malarial parasites and Leucocytozoon (36-67\%) in 5-15 days old nestlings have been previously reported (Fargallo and Merino, 2004; Zehtindjiev et al. 2012; CaleroRiestra and Garcia, 2016).

This study contributed to a better knowledge of the correlates of haemosporidian infection in wild birds in southwestern Europe. There was no evidence that anthropogenic pressure impacted the prevalence of haemosporidians in this common passerine species, the great tit, but we reported that parasite infection, even at low intensities, affects antioxidant defences of the birds. This result is of even greater significance because it is supported by previous evidence from another great tit population in a nearby study area of a different habitat type (Norte et al. 2009). Our results also show that great 
tits exposed to aerial emissions from pulp mills may incur in increased physiological harm when infected because both pollution exposure and haemosporidian infection affect their oxidative balance, with potential increased detrimental impacts on their fitness. Further experimental studies manipulating haemosporidian infection and evaluating a wider range of oxidative stress markers will help to further elucidate the mechanisms of protection against these ubiquitous parasites.

\section{SUPPLEMENTARY MATERIAL}

The supplementary material for this article can be found at https://doi.org/10.1017/pao.2017.4

\section{ACKNOWLEDGEMENTS}

We thank Miguel Mendonça, Nicolas Muscará, Miguel Araújo, Paulo Encarnação, Hugo Laborda, Sandra Antunes and Paulo Tenreiro for help with fieldwork. Pedro Melo, Ana Maria Donato Almeida da Silva, Maria Augusta Fernandes dos Santos and Maria Teresa Lopes Silva for the valuable suggestions about blood collection and laboratory procedures; Central Nacional de Anilhagem for providing bird rings; the Mata de Quiaios field station for fieldwork permission; Isabel Abrantes and the Nematology section of the Department of Life Sciences, University of Coimbra, for providing laboratory facilities; and Parque Florestal de Monsanto for kindly providing nest boxes.

\section{FINANCIAL SUPPORT}

This study was financially supported by Fundação para Ciência e a Tecnologia by the strategic program of MARE (MARE - UID/MAR/04292/ 2013) and the fellowships to Ana Cláudia Norte (SFRH/BPD/108197/2015 and SFRH/BD/ 13594/2003). This work was also supported by Coordenação de Aperfeiçoamento de Pessoal de Nível Superior (CAPES) and Conselho Nacional de Pesquisa e Tecnologia (CNPq), Brazil.

\section{CONFLICT OF INTEREST}

None.

\section{ETHICAL STANDARDS}

Bird capturing and sample collection complied with ethical standards and was performed with permission from national authorities.

\section{REFERENCES}

Ames, B., Shigenaga, M. and Hagen, T. (1993). Oxidants, Antioxidants, and the Degenerative Diseases of Aging. Proceedings of the National Academy of Sciences of the United States of America 90, 79157922.

Antunes, S. I. C. (2007). Prevalência de Hemosporídeos em Passeriformes no Centro de Portugal. MsC thesis. Department of Zoology, University of Coimbra, Coimbra.
Asghar, M., Hasselquist, D., Hansson, B., Zehtindjiev, P., Westerdahl, H. and Bensch, S. (2015). Hidden costs of infection: chronic malaria accelerates telomere degradation and senescence in wild birds. Science 347, 436-438.

Behnke, J., McGregor, P., Cameron, J., Hartley, I., Shepherd, M., Gilbert, F., Barnard, C., Hurst, J., Gray, S. and Wiles, R. (1999) Semi- quantitative assessment of wing feather mite (Acarina) infestations on passerine birds from Portugal. Fournal of Zoology of London 248, 337-347.

Bichet, C., Scheifler, R., Cœurdassier, M., Julliard, R., Sorci, G. and Loiseau, C. (2013). Urbanization, trace metal pollution, and malaria prevalence in the house sparrow. PLOS ONE 8, e53866.

Bradford, M. M. (1976). A rapid and sensitive method for the quantitation of microgram quantities of protein utilizing the principle of protein-dye binding. Analytical Biochemistry 72, 248-254.

Brown, M. E. (1996). Assessing body condition in birds. Current Ornithology 13, 67-135.

Calero-Riestra, M. and Garcia, J. T. (2016). Sex-dependent differences in avian malaria prevalence and consequences of infections on nestling growth and adult condition in the Tawny pipit, Anthus campestris. Malaria fournal 15, 178

Campbell, T. W. (1994). Hematology. In Avian Medicine: Principles and Applications (ed. Ritchie, B. W., Harrison, G. J. and Harrison, L. R.), Wingers Publishing, Florida, pp.176-198.

Cellier-Holzem, E., Esparza-Salas, R., Garnier, S. and Sorci, G. (2010). Effect of repeated exposure to Plasmodium relictum (lineage SGS1) on infection dynamics in domestic canaries. International Fournal of Parasitology 40, 1447-1453.

Chasar, A., Loiseau, C., Valkiūnas, G., Iezhova, T., Smith, T. B. and Sehgal, R. N. M. (2009). Prevalence and diversity patterns of avian blood parasites in degraded African rainforest habitats. Molecular Ecology 18, 4121-4133.

Cornet, S., Nicot, A., Rivero, A. and Gandon, S. (2013). Malaria infection increases bird attractiveness to uninfected mosquitoes. Ecology Letters 16, 323-329.

Cosgrove, C. L., Wood, M. J., Day, K. P. and Sheldon, B. C. (2008). Seasonal variation in Plasmodium prevalence in a population of blue tits Cyanistes caeruleus. Fournal of Animal Ecology 77, 540-548.

Costantini, D. and Møller, A. P. (2009). Does immune response cause oxidative stress in birds? A meta-analysis. Comparative Biochemistry and Physiology Part A: Molecular \& Integrative Physiology 153, 339-344. doi: http://dx.doi.org/10.1016/j.cbpa.2009.03.010

Dobson, A. and Foufopoulos, J. (2001). Emerging infectious pathogens of wildlife. Philosophical Transactions of the Royal Society of London Series B; Biological Sciences 356, 1001-1012.

Dufva, R. (1996). Blood parasites, health, reproductive success and egg volume in female great tits Parus major. Fournal of Avian Biology 27, 83-87. Evans, K. L., Gaston, K. J., Sharp, S. P., McGowan, A., Simeoni, M. and Hatchwell, B. J. (2009). Effects of urbanisation on disease prevalence and age structure in blackbird Turdus merula populations. Oikos 118, 774-782.

Fair, J. M., Whitaker, S. and Pearson, B. (2007). Sources of variation in haematocrit in birds. Ibis 149, 535-552.

Fargallo, J. A. and Merino, S. (2004). Clutch size and haemoparasite species richness in adult and nestling blue tits. Ecoscience 11, 168-174.

Figuerola, J., Munoz, E., Gutierrez, R. and Ferrer, D. (1999). Blood parasites, leucocytes and plumage brightness in the cirl bunting, Emberiza cirlus. Functional Ecology 13, 594-601.

Figuerola, J., Domènech, J. and Senar, J. C. (2003). Plumage colour is related to ectosymbiont load during moult in the serin, Serinus serinus: an experimental study. Animal Behaviour 65, 551-557.

Fokidis, H. B., Greiner, E. C. and Deviche, P. (2008). Interspecific variation in avian blood parasites and haematology associated with urbanization in a desert habitat. Fournal of Avian Biology 39, 300-310.

Garvin, M. C., Szell, C. C. and Moore, F. R. (2006). Blood parasites of Nearctic-Neotropical migrant passerine birds during spring trans-gulf migration: impact on host body condition. Fournal of Parasitology 92, 990-996.

Grasman, K. A., Fox, G. A., Scanlon, P. F. and Ludwig, J. P. (1996). Organochlorine-associated immunosuppression in prefledgling Caspian terns and herring gulls from the Great Lakes: an ecoepidemiological study. Environmental Health Perspectives 104, 829-842.

Gross, W. B. and Siegel, H. S. (1983). Evaluation of the Heterophil/ Lymphocyte Ratio as a Measure of Stress in Chickens. Avian Diseases 27, 972-979.

Hatchwell, B. J., Wood, M. J., Anwar, M. and Perrins, C. M. (2000). The prevalence and ecology of the haematozoan parasites of European blackbirds, Turdus merula. Canadian Fournal of Zoology 78, 684-687. 
Hawley, D. M., Hallinger, K. K. and Cristol, D. A. (2009) Compromised immune competence in free-living tree swallows exposed to mercury. Ecotoxicology 18, 499-503.

Isaksson, C., Sepil, I., Baramidze, V. and Sheldon, B. (2013) Explaining variance of avian malaria infection in the wild: the importance of host density, habitat, individual life-history and oxidative stress. $B M C$ Ecology 13, 15

Juuti, S., Vartiainen, T., Joutsenoja, P. and Ruuskanena, J. (1996) Volatile organochlorine compounds formed in the bleaching of pulp with $\mathrm{ClO}_{2}$. Chemosphere 33, 437-448.

Kenow, K. P., Grasman, K. A., Hines, R. K., Meyer, M. W., GendronFitzpatrick, A., Spalding, M. G. and Gray, B. R. (2007). Effects of methylmercury exposure on the immune function of juvenile common loons (Gavia immer). Environmental Toxicology and Chemistry 26, 1460 1469

Kleindorfer, S., Lambert, S. and Paton, D. C. (2006). Ticks (Ixodes sp.) and blood parasites (Haemoproteus spp.) in New Holland Honeyeaters (Phylidonyris novaehollandiae): evidence for site specificity and fitness costs. Emu 106, 113-118. doi: http://dx.doi.org/10.1071/MU05055

Knowles, S. C. L., Wood, M. J., Alves, R., Wilkin, T. A., Bensch, S. and Sheldon, B. C. (2011). Molecular epidemiology of malaria prevalence and parasitaemia in a wild bird population. Molecular Ecology 20, 10621076

Kostelecka-Myrcha, A., Pinowski, J. and Tomek, T. (1973). Changes in the hematological values during the nestling period of the Great Tit (Parus major L.). Bulletin de L'Academie Polonaise des Sciences 21, 725-732. Kozlov, M. V., Brodskaya, N. K., Haarto, A., Kuusela, K., Schafer, M. and Zverev, V. (2005). Abundance and diversity of human-biting flies (Diptera: Ceratopogonidae, Culicidae, Tabanidae, Simuliidae) around a nickel-copper smelter at Monchegorsk, northwestern Russia. Fournal of Vector Ecology 30, 263-271

Krams, I. A., Suraka, V., Rantala, M. J., Sepp, T., Mierauskas, P., Vrublevska, J. and Krama, T. (2013). Acute infection of avian malari impairs concentration of haemoglobin and survival in juvenile altricial birds. Fournal of Zoology 291, 34-41.

Lindström, K. M., Hawley, D. M., Davis, A. K. and Wikelski, M. (2005). Stress responses and disease in three wintering house finch (Carpodacus mexicanus) populations along a latitudinal gradient. General and Comparative Endocrinology 143, 231-239.

Martin, L. B. and Boruta, M. (2014). The impacts of urbanization on avian disease transmission and emergence. In Avian Urban Ecology. Behavioural and Physiological Adaptations (eds. Gil, D., and Brumm, H.), pp. 116-128. Oxford University Press, Oxford

Marzal, A., Lope, F. D., Navarro, C. and Møller, A. P. (2005). Malarial parasites decrease reproductive success: an experimental study in a passerine bird. Oecologia 142, 541-545.

Marzal, A., Balbontín, J., Reviriego, M., García-Longoria, L. Relinque, C., Hermosell, I. G., Magallanes, S., LópezCalderón, C., de Lope, F. and Møller, A. P. (2015). A longitudinal study of age-related changes in Haemoproteus infection in a passerine bird. Oikos 125, 1092-1099.

Meister, A. and Anderson, M. E. (1983). Glutathione. Annual Review of Biochemistry 52, 711-760.

Merino, S., Moreno, J., Sanz, J. J. and Arriero, E. (2000). Are avian blood parasites pathogenic in the wild? A medication experiment in blue tits (Parus caeruleus). Proceedings of the Royal Society of London B 267, $2507-2510$.

Navarro, C., Marzal, A., de Lope, F. and Møller, A. P. (2003). Dynamics of an immune response in house sparrows Passer domesticus in relation to time of day, body condition and blood parasite infection. Oikos 101, 291-298.

Norte, A. C., Araújo, P. M., Sampaio, H. L., Sousa, J. P. and Ramos, J. A. (2009). Haematozoa infections in a Great Tit Parus major population in Central Portugal: relationships with breeding effort and health. Ibis $\mathbf{1 5 1}$ 677-688.

Norte, A., Sheldon, B., Sousa, J., Tavares, P., Pereira, M., Duarte, A. and Ramos, J. (2010). Are great tits (Parus major) inhabiting the vicinity of a pulp mill healthy? Impacts on physiology and breeding performance. Archives of Environmental Contamination and Toxicology 59 502-512.

Norte, A. C., Lobato, D. N., Braga, E. M., Antonini, Y., Lacorte, G., Goncalves, M., Lopes de Carvalho, I., Gern, L., Nuncio, M. S. and Ramos, J. A. (2013). Do ticks and Borrelia burgdorferi s.l. constitute a burden to birds? Parasitology Research 112, 1903-1912.

O'Brien, E. L., Morrison, B. L. and Johnson, L. S. (2001). Assessing the effects of haematophagous ectoparasites on the health of nestling birds: haematocrit vs haemaglobin levels in House Wrens parasitized by blow fly larvae. Fournal of Avian Biology 32, 73-76.

Ortego, J. and Espada, F. (2007). Ecological factors influencing disease risk in Eagle Owls Bubo bubo. Ibis 149, 386-395.

Ots, I. and Hõrak, P. (1998). Health impact of blood parasites in breeding great tits. Oecologia 116, 441-448.

Paglia, D. E. and Valentine, W. N. (1967). Studies on the quantitative and qualitative characterization of erythrocyte glutathione peroxidase. Fournal of Laboratory and Clinical Medicine 70, 158-169.

Pérez-Tris, J., Carbonell, R. and Tellería, J. L. (2002). Parasites and the blackcap's tail: implications for the evolution of feather ornaments. Biological Fournal of the Linnean Society 76, 481-492.

Shurulinkov, P. and Chakarov, N. (2006). Prevalence of blood parasites in different local populations of reed warbler (Acrocephalus scirpaceus) and great reed warbler (Acrocephalus arundinaceus). Parasitology Research 99 588-592.

Silva, I. B. M. and Santos, H. M. (1991). Análise quantitativa do glutatião-redutase e da glutatião-peroxidase em plasma e eritrócitos humanos. Revista Portuguesa de Farmácia 41, 9-14.

Snoeijs, T., Dauwe, T., Pinxten, R., Vandesande, F. and Eens, M. (2004). Heavy Metal Exposure Affects the Humoral Immune Response in a Free-Living Small Songbird, the Great Tit (Parus major). Archives of Environmental Contamination and Toxicology 46, 399-404

Sol, D., Jovani, R. and Torres, J. (2000). Geographical variation in blood parasites in feral pigeons: the role of vectors. Ecography 23, 307-314. Sol, D., Jovani, R. and Torres, J. (2003). Parasite mediated mortality and host immune response explain age-related differences in blood parasitism in birds. Oecologia 135, 542-547.

Spurgin, L. G., Illera, J. C., Padilla, D. P. and Richardson, D. S. (2012). Biogeographical patterns and co-occurrence of pathogenic infection across island populations of Berthelot's pipit (Anthus berthelotii). Oecologia 168, 691-701.

StoraEnso (2004). EMAS declaração ambiental industrial - Celbi. Figueira da Foz.

StoraEnso (2005). Sustainability annual report. London.

Telfer, S., Lambin, X., Birtles, R., Beldomenico, P., Burthe, S. Paterson, S. and Begon, M. (2010). Species interactions in a parasite community drive infection risk in a wildlife population. Science 330, 243-246. Thompson, C. W., Hillgarth, N., Leu, M. and McClure, H. E. (1997) High parasite load in house finches (Carpodacus mexicanus) is correlated with reduced expression of a sexually selected trait. The American Naturalist 149, 270-294

Tomás, A. F. V. (2014). Rastreio parasitológico em aves selvagens de zona periurbanas do Litoral e Interior de Portugal. MsC thesis. Departamento de Biologia Animal, University of Lisbon, Lisbon.

Václav, R., Ficová, M., Prokop, P. and Betáková, T. (2011) Associations between coinfection prevalence of Borrelia lusitaniae, Anaplasma, Rickettsia sp. in hard ticks feeding on reptile hosts. Microbial Ecology 61, 245-253.

Valkiūnas, G. (2005). Avian Malaria Parasites and Other Haemosporidia. CRC Press, Boca Raton.

Valkiūnas, G., Zičkus, T., Shapoval, A. P. and Iezhova, T. A. (2006) Effect of Haemoproteus belopolskyi (Haemosporida: Haemoproteidae) on Body Mass of the Blackcap Sylvia atricapilla. Fournal of Parasitology $\mathbf{9 2}$, 1123-1125.

Valkiūnas, G., Iezhova, T. A., Krizanauskiene, A., Palinauskas, V., Sehgal, R. N. M. and Bensch, S. (2008). A comparative analysis of microscopy and Pcr-based detection methods for blood parasites. Fournal of Parasitology 94, 1395-1401.

van Kampen, E. J. and Zijlstra, W. G. (1961). Standardization of hemoglobinometry II. The hemiglobincyanide method. Clinica Chimica Acta 6 538-544

Ventim, R., Tenreiro, P., Grade, N., Encarnação, P., Araújo, M., Mendes, L., Pérez-Tris, J. and Ramos, J. (2012). Characterization of haemosporidian infections in warblers and sparrows at south-western European reed beds. Fournal of Ornithology 153, 505-512.

Wood, M. J., Cosgrove, C. L., Wilkin, T. A., Knowles, S. C. L. Day, K. P. and Sheldon, B. C. (2007). Within-population variation in prevalence and lineage distribution of avian malaria in blue tits, Cyanistes caeruleus. Molecular Ecology 16, 3263-3273.

Zehtindjiev, P., Križanauskienè, A., Scebba, S., Dimitrov, D., Valkiūnas, G., Hegemann, A., Tieleman, B. I. and Bensch, S (2012). Haemosporidian infections in skylarks (Alauda arvensis): a comparative PCR-based and microscopy study on the parasite diversity and prevalence in southern Italy and the Netherlands. European Fournal of Wildlife Research 58, 335-344. 